\title{
Evaluating the Embodied Agent Effect in an English as a Foreign Language Learning Environment
}

\author{
Talvany Carlotto ${ }^{1}$, Patricia Jaques ${ }^{1}$ \\ ${ }^{1}$ Programa Interdisciplinar de Pos-Graduacao em Computacao Aplicada (PIPCA) \\ Universidade do Vale do Rio dos Sinos (UNISINOS) \\ talvanynet@gmail.com, pjaques@unisinos.br
}

\begin{abstract}
The use of Pedagogical Animated Agents is considered a very effective way of improving learning, and some of their aspects can be evaluated in a computer system in terms of what authors have been calling the 'Embodied Agent Effect'. However, no research has been found on how the 'Embodied Agent Effect' affects students' learning in a foreign language learning system. Aiming at evaluating this effect, this paper describes an experiment with forty-two Brazilian undergraduate students with intermediate level of English using a web-based learning system containing one of the two versions of the agent: static or embodied. Data collected from pretests and posttests were evaluated using the paired t-test. Results revealed that the students had better results after using the system, but the Embodied Agent Effect was not evidenced in the experiment.
\end{abstract}

Resumo. “Avaliando o Efeito do Agente Corporificado em um Ambiente de Aprendizagem de Inglês como Lingua Estrangeira" (Title in Portuguese)

Agentes Pedagógicos Animados são considerados uma forma eficaz de melhorar a aprendizagem, e alguns de seus aspectos podem ser avaliados em termos do que os autores vem chamando de efeito do agente corporificado (Embodied Agent Effect). Entretanto, não foram encontrados projetos de pesquisa sobre esse efeito em um sistema de aprendizado de idiomas. No experimento que esse artigo descreve, quarenta e dois alunos universitários brasileiros com nível intermediário de inglês usaram um sistema web contendo uma das duas versões do agente: estática ou corporificada. Os dados foram coletados com o uso de pré e pós-testes e avaliados usando teste t-pareado. Os resultados revelaram que os alunos tiveram melhor resultado depois de usar o sistema, mas o Efeito do Agente Corporificado não foi encontrado no experimento.

\section{Introduction}

According to Brown (2000), teaching a foreign language takes more than just applying a set of methods that makes the teaching process successful. The teacher must guide and facilitate learning, enabling the student to learn and setting the conditions required to the acquisition of the new knowledge.

Computers systems have been built in order to facilitate this process of learning a foreign language. They are comprised by the field of Computer-Assisted Language Learning (CALL), which relies on language theories in addition to computer science principles [Levy 1997]. In short, research in CALL studies how computers can help 
language learning. One strong issue that has to be considered in the development of CALL systems is how to expose the student to social interactions. The use of Animated Pedagogical Agents (APAs) can facilitate this exposure to the language [Dowling 2000].

Through the years, research has been done on evaluating APAs in computer environments [Johnson et al. 1998, Reategui et al. , Lester and Stone 1997]. One of the constant issues on such works, though, is how to evaluate the agents, that is, what aspects of the agent should be considered in the evaluation.

Atkinson (2002) proposed three agent effects to take into consideration when evaluating APAs: (i) the 'Image Effect' evaluates how much the image of the agent on the screen helps in learning, (ii) the 'Embodied Agent Effect' studies how to simulate the student-instructor relationship and the (iii) 'Modality Effect' states that orally-delivered instruction helps more in learning than textually-delivered instruction. Some authors have been using this agent effects theory to study and evaluate agents [Dunsworth and Atkinson 2007, Atkinson 2002]. However, no research has been found on evaluating these effects on language learning systems.

This article reports the study of one of those three effects, the Embodied Agent Effect, in an experiment involving an APA in a web-based CALL system. To evaluate this effect, a group of undergraduate students with intermediate level of English used a language learning computer system created for the project. Half the students used the system with a more static version of the agent, while the other half used the system with an embodied version of the agent. The results of both groups were compared in order to evaluate the Embodied Agent Effect.

This paper is organized as follows. Section 2 presents an overview of APAs and the effects proposed by Atkinson (2002), followed by some related work in Section 3. The system and the experiment are described in Sections 4 and 5. The analysis of the data and some final remarks are discussed in Sections 6 and 7.

\section{Animated Pedagogical Agents and the Embodied Agent Effect}

Pedagogical Agents are intelligent agents that have an educational or pedagogical role to facilitate or to improve the student's learning [Gurer 1998]. When they take the form of visible characters on the screen of multimedia learning environments they are called Animated Pedagogical Agents (APAs) [Moreno 2005, Schroeder and Adesope 2012]. APAs can exhibit various types of life-like behaviours, such as speech, emotions, gestures and eye, head and body movements [Dehn and van Mulken 2000]. Such characters can serve numerous pedagogical roles, such as instructors, coaches, tutors, and learning companions [Chou et al. 2003, Baylor and Kim 2005, Haake and Gulz 2009].

According to Dehn (2000), as APAs' behaviours somehow mimic the social exchange present in human interactions, they are considered a powerful addition to multimedia learning environments because they allow these environments to exploit verbal as well as nonverbal forms of communication [Atkinson 2002, Atkinson et al. 2005]. Furthermore, some research works [Reategui et al., Jeung et al. 1997, Mousavi et al. 1995] have indicated that APAs can be used during the learning process as an interesting resource to reduce the cognitive load of the student. 
Moreno and Mayer (2000) have proposed a way to analyze the several questions related to the cognitive and affective impact of the agents. They measured the agents' impact on learning by what the authors called Embodied Agent Effect, Image Effect, and Modality Effect [Moreno and Mayer 2000].

The Image Effect explores the visual presence of the agent during learning. It measures the impact of the presence of the agent on learner performance and attitudes. Lester and Stone (1997) have affirmed that even if the agent is not expressive, the mere presence of the agent can positively affect the learning experience of the student. According to them, students have said that learning with the animated agent is more enjoyable than without it. In order to evaluate the Image Effect, they suggest to compare two aurally-delivered instructions, one of them with the presence of the agent on the screen and the other one without the agent [Dunsworth and Atkinson 2007].

The Modality Effect studies the modality principle. According to the modality principle, the textual information should be presented to the students orally instead of by written words [Mayer 2001]. According to [Ginns 2005], this principle states that learning increases if the textual information is presented by audio and with related visual information. Ginns (2005) successfully proved this principle, but some other authors [Schueler et al. 2008] affirm that, under certain circumstances, the modality principle does not apply.

The Embodied Agent Effect makes use of a fully embodied agent that delivers aural instructions. The effect compares results of instructions delivered by the agent and instructions delivered simply by text [Dunsworth and Atkinson 2007]. The agent may direct a learner's attention by moving around the screen, using gaze and gestures, providing nonverbal feedback, and conveying emotions [Atkinson 2002]. According to Atkinson (2002), an agent with those characteristics of instruction delivery is capable of simulating the student-instructor relationship, and thus might facilitate learning [Atkinson 2002]. This aspect was demonstrated also in [Craig et al. 2002]. They have compared learning performance of students that interacted with animated agents with students whose interactions were only with static agents. Comparing the results of students that have interacted with two different versions of the same agent, one version static and another version fully embodied (control and experiment group), presents itself as a good way to demonstrate the Embodied Agent Effect.

\section{Related Work}

Research on the use of APAs is not new. The use of animated agents in learning systems have been explored over the years. In the medical field, the agent Adele assists students in the diagnostic of diseases of simulated patients [Johnson et al. 1998]. In different domains, the agent Kurrupako teaches algorithms [Reategui et al. ] and the agent Herman teaches botanic and physiology [Lester and Stone 1997]. Pedagogical agents have also been used to improve learning in CALL systems. Some examples include the works of Choi (2006), Galluccio (2008), Theodoridou (2009), Ko (2010), and Sabet and Shalmani (2010).

Regarding the agent effects studied on this article, there is, for instance, Atkinson (2002). Atkinson used an animated pedagogical agent to optimize a computer-based learning environment designed to teach learners how to solve word problems. The agent 
could deliver instruction either textually or orally, using gaze and gesture to direct the focus of the students on the relevant parts of the example. Final results were consistent with the Embodied Agent Effect and the Image Effect. The Modality Effect, however, was not found in the experiment, since participants that had instruction delivered orally and without the agent did not outperform participants who had instruction delivered textually and without the agent.

Dunsworth and Atkinson (2007) also studied the agent effects. Their work aimed at evaluating the Modality Effect, the Embodied Agent Effect, and the Image Effect in a system that lectured about the human circulatory system. Results of the study could not attest the Modality Effect in the agent, but the Embodied Agent Effect and the Image Effect were both present. The conclusion of the study was that an agent programmed to coordinate narration with gaze and pointing incorporated into a science-focused multimedia-learning environment can foster learning.

The works described here are very significant contributions to the field of the agent effects. However, they evaluated the effect in very specific fields - Math and Medicine. No significant work was found that evaluated the agent effects in foreign language learning systems. This paper presents the evaluation of the Embodied Agent Effect in a language learning system.

\section{The Web-based Learning System}

A CALL system was created to this project with the purpose of evaluating the Embodied Agent Effect in an English learning system for Brazilian students. The system was developed as a website, to facilitate its access in a computer laboratory, and the subject of learning chosen for the system was the present perfect tense. According to Sklar (2011), teaching the English present perfect tense to native speakers of Brazilian Portuguese is one of the biggest challenges for teachers. A system that helps Brazilian students learn the present perfect tense is an attempt to make that learning more productive and enjoyable.

The architecture of the system is composed of JavaServer Pages (JSPs), Java Servlet classes and regular Java classes, following the Model-View-Controller (MVC) Model. The basic architecture of the system is represented in Figure 1. The users interact with the system making requests to the JSP pages (View in MVC), while the JSP Pages send their requests to the Servlets (Controller in MVC). Finally, the Servlets call regular Java classes (Model) to execute the request.

The web-based learning system consists of four content sections and four exercises sections. The content sections are presented in Mod_1.jsp and processed by Servlet Mod1.java. The exercises sections are presented in Mod_1_Ex.jsp and processed by four servlets, one per exercise: Mod1Ex1.java, Mod1Ex2.java, Mod1Ex3.java, Mod1Ex4.java. The material for the content and for the exercises was adapted from the seventh chapter of Murphy's book English Grammar in Use [Murphy 2004]. The sections of content exercises are presented in a sequence of screens. The student goes to the next screen by clicking on the button Next. The content screens contain text, tables and images altogether to present the material. The exercises screens contain the exercises and a Verify button. The user can fill in the answers of the exercise and click on Verify in order to check if the answer provided is correct. The first exercise involves structuring simple statements using the present perfect. The second exercise requires structuring present perfect statements 
Figura 1. The basic architecture of the system

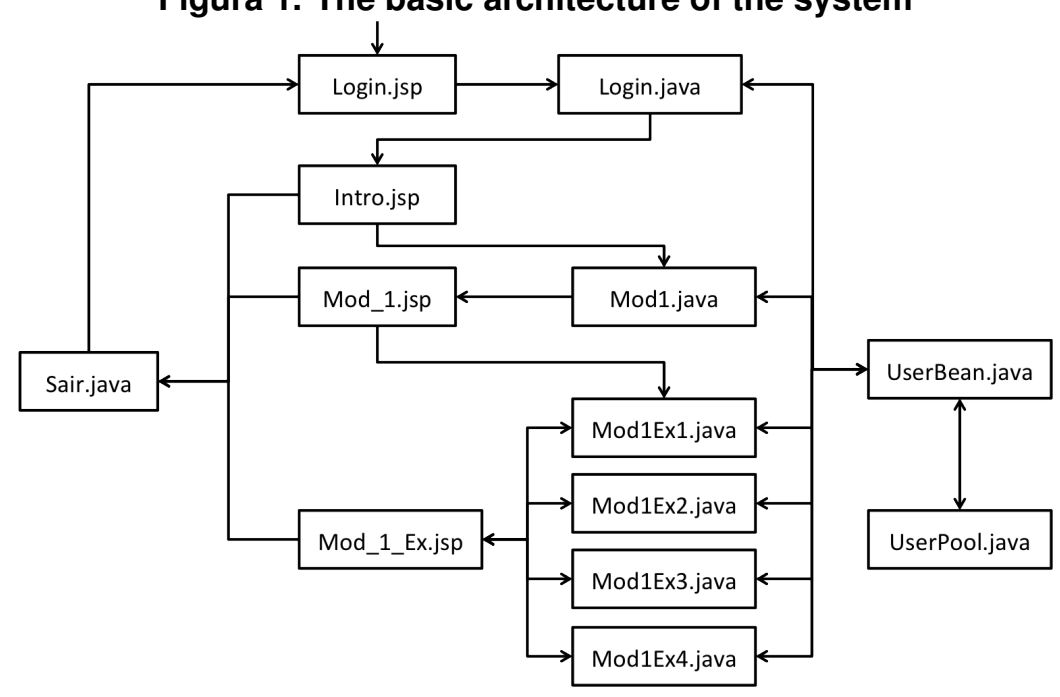

using just, already or yet - it is identified for each statement which adverb should be used. The third exercise evaluates the composition of statements using the same three adverbs from the exercise two, but this time the student has to decide which adverb to use. Finally, the fourth exercise asks the student to choose between been and gone for simple statements. After the completion of the four exercises, a closure message is displayed.

In order to evaluate the Embodied Agent Effect, two different versions of the learning system were developed: (i) the static version contains the agent standing on the right corner of the screen and speaking. While she speaks, the content that she is talking about is highlighted, i.e. the color of the area of content changes its color from white to light blue (see Figure 2); (ii) the embodied version contains the agent in its complete form: speaking, moving and pointing to the content (see Figure 3).

Figura 2. Patti on the static version of the system

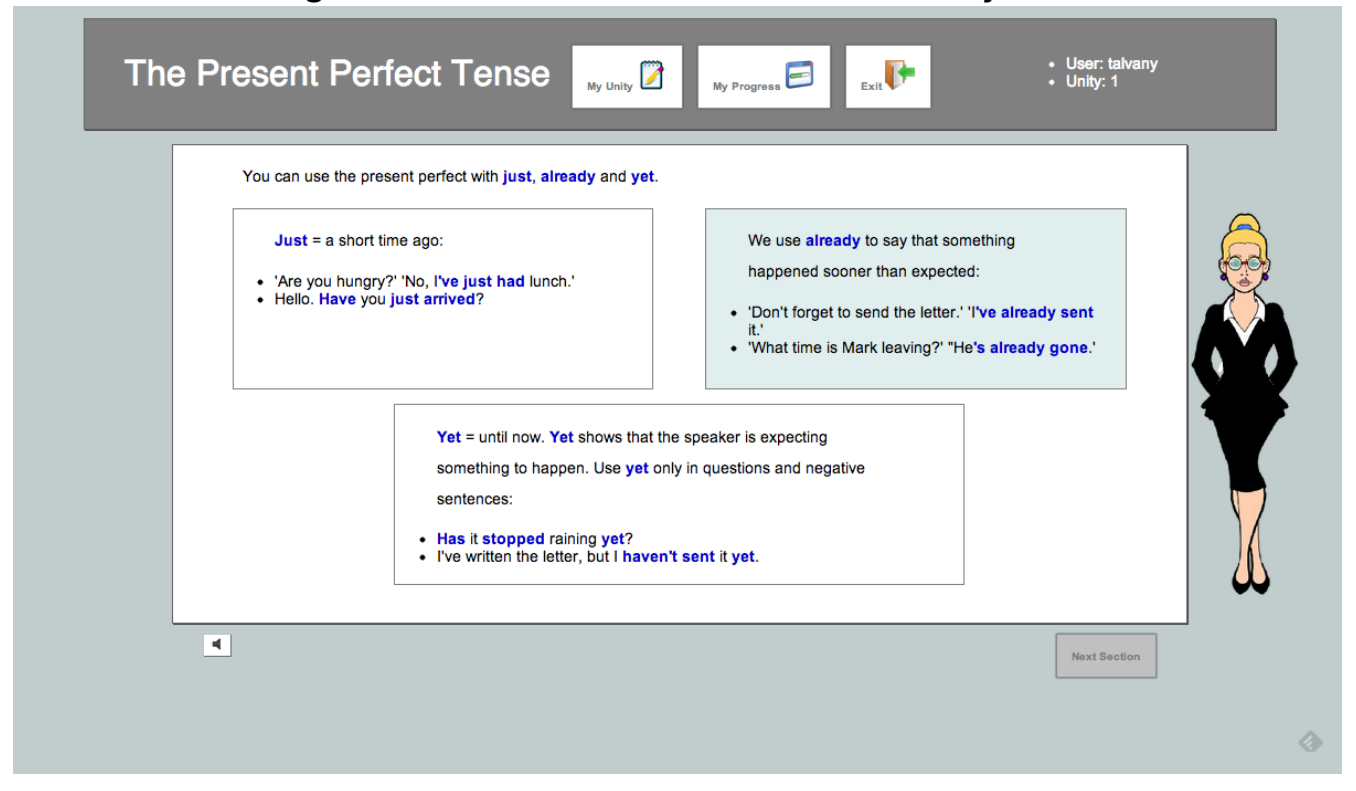

The Embodied Agent Effect states that an agent able to simulate the 
Figura 3. Patti pointing to the content

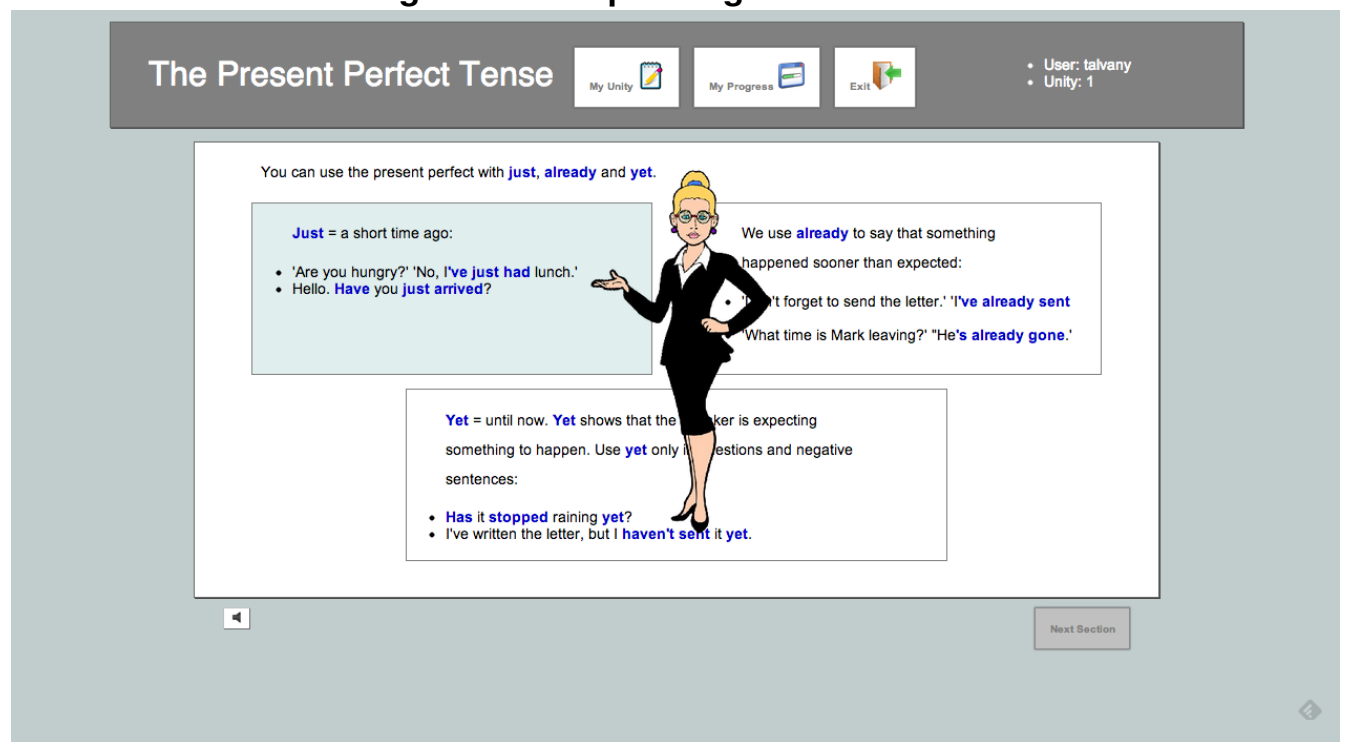

student-instructor relation by moving, gazing, and delivering auditory messages, can facilitate learning [Atkinson 2002]. In this project, the Embodied Agent Effect was evaluated by comparing the performance improvement of students that used the static version of the agent in relation to students that used the embodied version of the agent. It was predicted that the participants assigned to the embodied version would have significantly better learning gains than their peers from the static version of the agent.

\subsection{The APA}

Patti is an animated agent designed specifically for this project. She was animated using the DIVAlite framework. DIVAlite is a software tool dedicated to the animation of non-verbal behaviour of web-based embodied conversational agents [Sansonnet et al. 2012]. It enables the integration of an animated agent into a webpage interacting with Document Object Model (DOM) elements of the page. There are a few standard characters available in DIVAlite, and they all have basic movements already incorporated. However, it is also possible to create new agents. To do that, it is sufficient to provide the framework with the images correspondent to each movement of the agent.

Figura 4. One of the drafts for Patti
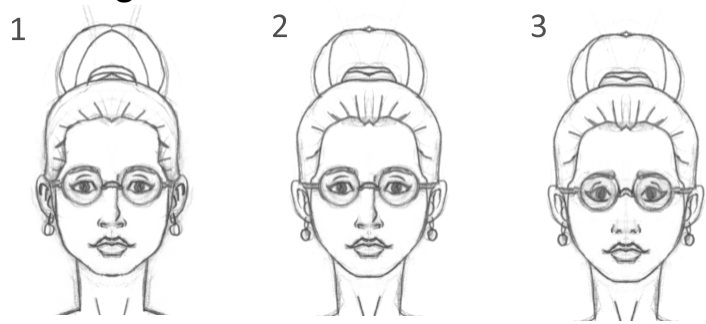

Patti is the representation of a wise, polite, disciplined, responsible and trustworthy teacher. She greets the student and introduces herself on the first screen, explains the material on the content screens and reacts to the results of the students on the exercises. The drawings of Patti and of her movements were made in pencil, and 
later digitalized using photoshop (see Figure 4). Her voice was recorded using an ipod by a Brazilian teacher of EFL that acquired American accent after studying American pronunciation and living in the USA for a while.

\section{The Evaluation Experiment}

In the experiment, participants were first submitted to a pretest, followed by the web-system and then by a posttest (Figure 5). In total, the experiment took about one hour for each group of students.

Figura 5. A diagram describing the experiment

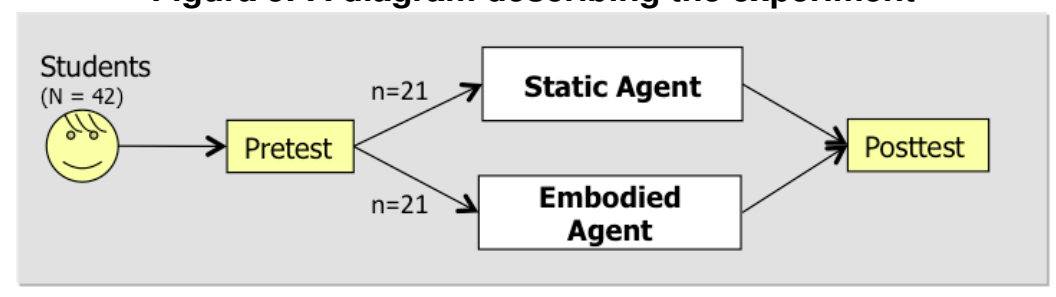

\subsection{Participants}

The participants were Brazilian undergraduate students from different courses of a Southern Brazilian university. They were all enrolled in classes that require pre-intermediate level of English as prerequisite and participated in the study as a regular class activity. In total, the data of forty-two students who participated in the experiment were considered valid.

\subsection{Procedure}

The experiment was conducted in computer laboratories at the university. Instructions about the experiment were given to the students in Portuguese, their native language. However, the whole system, including explanations, audio content and menus, was in English. The pretest and postest questions were also in English.

Each student received an individual username to access the system, along with the password and a number corresponding to the system randomly assigned to him or her. Students assigned to the control group used the version of the system containing the static agent. The experimental group interacted with the embodied agent. The first part of the experiment was a paper and pencil pretest. The only information they should provide with the tests, besides the answers, was the username they had received to access the system. After returning the pretest to the experimenter, the students accessed the system in the computer wearing headphones. In the system, the students received the instruction and then answered the postest.

\subsection{Pretest and posttest}

Students were submitted to a pretest and a posttest, before and after (respectively) interacting with the system, both based on Murphy's book. Each test had four exercises, with similar level of difficulty. Each exercise contained a group of questions aiming at evaluating a specific grammar point developed in the activity. The first exercise assessed the capacity of the student of structuring the present perfect tense in simple sentences, 
i.e. using have / has + past participle. The second and third exercises assessed the use of the adverbs just, already and yet in present perfect statements. While in the second exercise the correct adverb was informed, in the third exercise the student should choose the apropriate adverb for each statement. The fourth exercise assessed the correct use of been and gone in sentences built with the present perfect.

\section{Data Analysis}

Each test was analyzed and given a grade. The maximum grade was 10.0, and each of the four exercises was responsible for $25 \%$ of the total grade. A paired t-test was applied to the data in each group to verify if the true difference in means of each group was not equal to zero, i.e., if there was learning gain in each group (Table 1).

\begin{tabular}{lllll}
\multicolumn{4}{c}{ Tabela 1. Paired t-test results } \\
\hline & t & df & p-value & mean \\
\hline Group 1 & 3.5003 & 20 & 0.002253 & 1.398571 \\
Group 2 & 3.4319 & 20 & 0.00264 & 1.917143 \\
\hline
\end{tabular}

The paired t-test applied to the first group (the group with the simpler version of the agent) and to the second group (the group with the complete version of the agent) gives p-values 0.002253 and 0.00264 , respectively. Those values are lower than the significance level of 0.05 , so the null hypothesis is rejected in both cases. The means (1.398571 and 1.917143 , respectively) are not equal to zero and there was statistically significant improvement in performance in both groups.

The Embodied Agent Effect was evaluated comparing the performance gain (the difference between the posttest and pretest) between the static and the embodied versions of the system. An unpaired t-test was applied and it presented $\mathrm{p}$-value $0.454(\mathrm{t}=0.7569$; $\mathrm{df}=36.234$ ). That value is not lower than the significance level of 0.05 , so the null hypothesis is not rejected, meaning that the difference was no significant difference between the performance gain in groups 1 and 2, thus we cannot affirm that the agent demonstrated the Embodied Agent Effect.

\section{Final Remarks}

The goal of this study was to investigate the Embodied Agent Effect of the APA in the learning of the English present perfect tense. A total of forty-two undergraduate students, split into two groups, participated in the experiment. Students assigned to the control group used the version of the system containing the static agent, while the experimental group interacted with the embodied agent.

Students who used the embodied version of the agent did not have better performance than students who used the static version. Therefore, the embodied effect was not found and the results of this experiment do not support Dunsworth's and Atkinson's claims about the Embodied Agent Effect. One possible explanation for that is that the agent did not present many features that would make it embodied. It only moved to the content it was explaining and pointed to it. It is possible to suppose that, if more characteristics of a real human teacher were incorporated to the agent, maybe the results in the third group could be better. Research for more methods of making the agent as close to a real human-teacher as possible would be very useful. 


\section{Referências}

Atkinson, R. (2002). Optimizing learning from examples using animated pedagogical agents. Journal of Educational Psychology, 94:416-427.

Atkinson, R., Mayer, R., and Merrill, M. (2005). Fostering social agency in multimedia learning: Examining the impact of an animated agent's voice. Contemporary Educational Psychology, 30:117-139.

Baylor, A. L. and Kim, Y. (2005). Simulating instructional roles through pedagogical agents. Int. Journal of Artificial Intelligence in Education, 15(2):95-115.

Brown, D. (2000). Principles of Language Learning and Teaching. Addison Wesley Longman, New York, 4th ed. edition.

Choi, S. and Clark, R. E. (2006). Cognitive and affective benefits of animated pedagogical agents for learning a second language. Journal of Educational Computing Research, 34:441-466.

Chou, C. Y., Chan, T. W., and Lin, C. J. (2003). Redefining the learning companion: The past, present, and future of educational agents. Computers and Education, 40:255-269.

Craig, S. D., Gholson, B., and Driscoll, D. M. (2002). Animated pedagogical agents in multimedia educational environments. Journal of Educational Psychology, 94:428-434.

Dehn, D. M. and van Mulken, S. (2000). The impact of animated interface agents: A review of empirical research. International Journal of Human-Computer Studies, $52: 1-22$.

Dowling, C. (2000). Intelligent pedagogical agents in online learning environments. In Int. Conf. on Educational Uses of Communication and Information Technologies.

Dunsworth, Q. and Atkinson, R. K. (2007). Fostering multimedia learning of science: Exploring the role of an animated agent's image. Computers \& Education, 49(3):677-690.

Galluccio, R. (2008). Animated Pedagogical Agents as Spanish Language Instructors: Effect of Accent, Appearance, and Type of Activity on Student Performance, Motivation, and Perception of Agent. Florida State University.

Ginns, P. (2005). Meta-analysis of the modality effect. Learning and Instruction, 15(4):313-331.

Gurer, D. (1998). The use of distributed agents in intelligent tutoring. In ITS Workshop on Pedagogical Agents, pages 20-25, San Antonio, Texas.

Haake, M. and Gulz, A. (2009). A look at the roles of look \& roles in embodied pedagogical agents - a user preference perspective. Int. J. Artif. Intell. Ed., 19(1):39-71.

Jeung, H., Chandler, P., and Sweller, J. (1997). The role of visual indicators in dual sensory model instruction. Journal of Educational Psychology, 17:329-433.

Johnson, L., Shaw, E., and Ganeshan, R. (1998). Pedagogical agents on the web. In ITS workshop on pedagogical agents, pages 2-7. San Antonio, Texas. 
Ko, Y.-A. (2010). The effects of pedagogical agents on listening anxiety and listening comprehension in an english as a foreign language context. PhD thesis, Logan, UT, USA. AAI3433403.

Lester, J. C. and Stone, B. A. (1997). Increasing believability in animated pedagogical agents. In The First International Conference on Autonomous Agents, pages 16-21, New York. ACM Press.

Levy, M. (1997). Computer-Assisted Language Learning: Context and Conceptualization. Oxford University Press, New York.

Mayer, R. E. (2001). Multimedia learning. Cambridge University Press, New York.

Moreno, R. (2005). Multimedia learning with animated pedagogical agents. In Mayer, R., editor, The Cambridge Handbook of Multimedia Learning, pages 507-523.

Moreno, R. and Mayer, R. E. (2000). Life-like pedagogical agents in constructivist multimedia environments: Cognitive consequences of their interaction. In World Conference on Educational Multimedia Hypermedia, and Telecommunications (ED-MEDIA), pages 741-746.

Mousavi, S. Y., Low, R., and Sweller, J. (1995). Reducing cognitive load by mixing auditory and visual presentation modes. Journal of Educational Psychology, 87(2):319-334.

Murphy, R. (2004). English Grammar In Use with Answers: A Self-study Reference and Practice Book for Intermediate Students of English. Grammar in Use Series. Cambridge University Press.

Reategui, E. B., Ceron, R. F., Boff, E., and Vicari, R. M. Kurrupako : um agente animado sócio-afetivo para ambientes de aprendizagem. RENOTE.

Sabet, M. K. and Shalmani, H. B. (2010). Visual and spoken texts in mcall courseware: The effects of text modalities on the vocabulary retention of efl learners. English Language Teaching, 3:30.

Sansonnet, J. P., Correa, D. W., Jaques, P., Braffort, A., and Verrecchia, C. (2012). Developing web fully-integrated conversational assistant agents. In ACM Research in Applied Computation Symposium, pages 14-19, New York, NY, USA. ACM.

Schroeder, N. L. and Adesope, O. O. (2012). A case for the use of pedagogical agents in online learning environments. Journal of Teaching and Learning with Technology, $1: 43-47$.

Schueler, A., Scheiter, K., Gerjets, P., and Rummer, R. (2008). The modality effect in multimedia learning: theoretical and empirical limitations. In International conference for the learning sciences - V. 2, ICLS'08, pages 311-318. International Society of the Learning Sciences.

Sklar, F. A. (2011). Present but not perfect: A study of problems brazilian students encounter when learning the english present perfect tense. Master's thesis, Karlstads Universitet, Karlstad, Sweden.

Theodoridou, K. D. (2009). Learning with Laura: Investigating the Effects of a Pedagogical Agent on Spanish Lexical Acquisition. PhD thesis, The University of Texas at Austin, Texas, USA. 